patients with preexisting heart disease to a deterioration in the underlying cardiac condition. We would suggest that, if there is no positive evidence for this explanation, then pulmonary embolism should be considered as a possible cause.-We are, etc.

\section{W. J. WINDEBANK}

F. MORAN

Royal Infirmary,

Glasgow

Sasahara, A. A., Cannilla, J. E., Morse, R. L., Sidd, J. J., and Tremblay, G. M. American Gibbs, N. M., British fournal of Surgery, 1957,

Flanc, C., Kakkar, V. V., and Clarke, M. B. British fournal of Surgery, 1968, 55, 742. - Littmann, D., in Pulmonary Embolic Disease, ed. A. A. Sasahara and M. Stein, p.
York, Grune and Stratton, 1965 .

\section{Fractured Lippes Loop and Pregnancy}

SIR,-We have used the Lippes loop for eight years and have experience of about 1,000 cases. Our first case of fracture of the loop in utero occurred in December 1972. At about the same time there appeared two reports of similar observations. ${ }^{12}$

The Lippes loop was inserted in 1966 after a third induced abortion, the patient then being 37 years old. A yearly check-up showed no abnormality, and the loop caused no complaints. In November 1972 menstruation ceased, and in December pregnancy became obvious. The patient applied for interruption. Before evacuation of the uterus we attempted to remove the loop, but when the indicator suture was pulled out only a small part of the loop was found to be attached to it. A radiograph showed that three fragments of the loop were still in the uterus (see fig.). These parts were removed under general anaesthesia after the cervix had been dilated. The fractured parts fitted together.

After several years of use chemical changes in an intrauterine device may produce loss of rigidity that may lead to fracture. Fracture may affect the contraceptive action, as was evidently the case in this patient, who became pregnant at the age of 42 after six years of uneventful use of the device.-We are, etc.,

Z. DomáNY

M. HaNCsók

Budapest, Hungary

1 Last, P. A., fournal of Obstetrics and Gynaecology 2 of the British Commonwealth, 1972, 79, 190.
Childhood Leukaemia and Pregnancy Viraemia

SIR,-In answer to Dr. C. M. D. Edmonds (27 January, p. 235), given an expectation of 0.40 deaths per survey, no deaths would be found in about $67 \%$ of such surveys, one death in $27 \%$, two deaths in $5 \%$, and over two deaths in the remaining $1 \%$; these percentages are given as individual terms of the Poisson distribution. Thus to find no deaths in one such survey is hardly unusual.

But where the expectancy of a death is 0.15 per survey, two deaths would be found in less than $1 \%$ of surveys; in other words, to find two deaths in the one and only survey is significant at the $1 \%$ level.

The accumulation of large numbers is not necessary, in all circumstances, to suggest statistical or commonsense significance. To win a major pools dividend once is, perhaps, fortuitous: to win twice, suspicious. I am, etc.,

Oxford

R. H. LINDENBAUM

\section{AHF-related Protein and Precipitation Reactions}

SIR,-Dr. H. Ekert and others (30 December, p. 789) raised the question of the specificity of the antiserum we used when we investigated patients with von Willerbrand's disease (5 August, p. 317). We did not find IgM or lipoprotein by means of specific antisera in the purified antihaemophilic factor (AHF) which we used for immunization. The antiserum used was absorbed with one-tenth volume of normal plasma. The anti-AHF antibody was present in such large amounts that this absorption did not appreciably affect its titre. No difference was observed when the patients were tested with unabsorbed antiserum or antiserum ab sorbed with one-tenth volume of von Willebrand plasma.

We have recently had the opportunity of comparing our antiserum with those of other workers in this field (Drs. Bouma, of Utrecht; Meyer, of Paris; Kernoff, of Oxford; Prentice, of Glasgow; and Trobisch, of Marburg). All antisera gave lines of complete identity in double diffusion tests, indicating that one and the same von Willebrand antigen is determined by all. There is no doubt, however, that the antigen is heterogeneous, as demonstrated by cross-immuno-

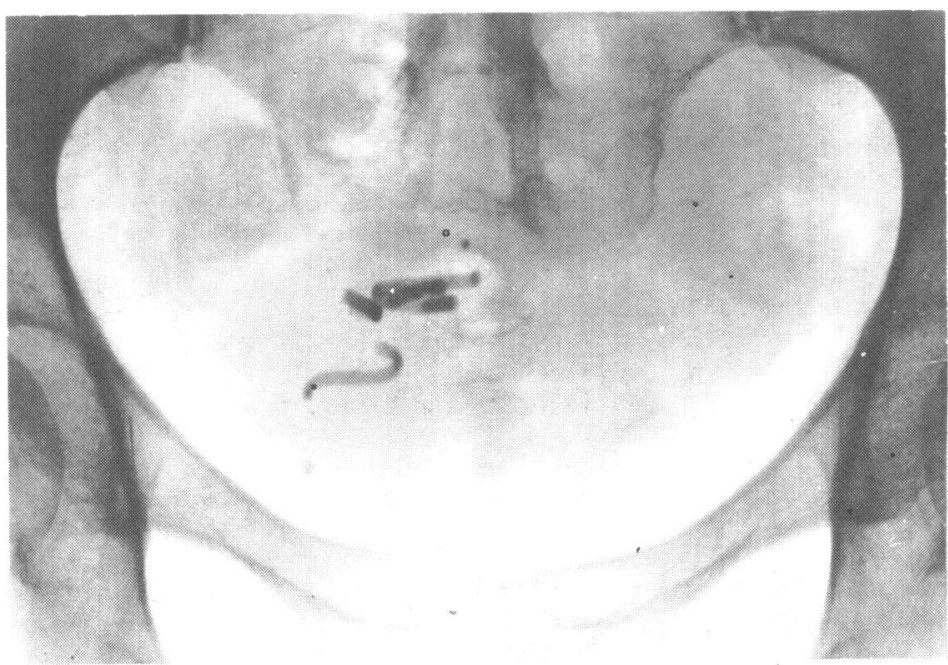

electrophoresis, and quantitative estimation by the Laurell technique must be carefully performed. An improved method is, however, under way.

We did not regularly test our patients with an inhibitory coagulation test, as the results of such methods are somewhat inconsistent.-We are, etc.

LARS HOLMBERG INGA MARIE NILSSON

Allmänna, Sjukhuset,

Malmö, Sweden

\section{Sympathomimetic Amines and}

Antidepressant Agents

SIR,-The very interesting and important research described by Dr. A. J. Boakes and others (10 February, p. 311) is reassuring in its suggestion that two monoamine oxidase inhibitors do not harmfully potentiate the effects on the blood pressure and pulse rate of four sympathomimetic amines. However, the authors' finding that imipramine produces a greater potentiation of these effects than do the monoamine oxidase inhibitors appears to be contrary to clinical experience.

Possibly this apparent anomaly results from the experimental design. One would expect clinical pharmacologists, forewarned by their knowledge of the risks of drug interaction, to be scared by lying down for three hours or so while four amines in succession are infused into them immediately after they have taken antidepressives. Their fear could magnify any cardiovascular actions of the amines under these conditions. Habituation would be likely to reduce the emotional reactions and, if I interpret the methodology rightly, each subject had infusions on four occasions. The authors do not say which they gave first, imipramine or the monoamine oxidase inhibitors, but I think it must have been the tricyclic drug because they mention it first in their description of the method and most clinicians believe that to give tricyclics before monoamine oxidase inhibitors is safer than vice versa.

If this sequence was indeed the one in which the experiment proceeded, it could perhaps explain also the statistically significant increase of resting blood pressure which the authors observed during the preliminary uncomplicated administration of imipramine and which likewise is the reverse of clinical experience. One would surmise that while the subjects were taking this drug in the early stages of their ordeal they were particularly apprehensive about what was in store for them.

I realize that Dr. Boakes and his colleagues probably dismissed additions to their design as making it so vast and complicated that they could not have put it into practice, but if they had given normal saline without amines as a fifth substance during each infusion they might have been able to distinguish pharmacological from psychological effects of interaction, whereas they could have thrown some light on the concurrence of imipramine medication and hypertension by a double-blind administration of a placebo instead of an antidepressive to another group of subjects undergoing the whole procedure.

I doubt whether from this research we need seriously suspect imipramine of inter- 